\title{
Detection of Cocaine and Amphetamine Regulated Transcript in the abomasum of slaughtered bulls with different daily body weight gains
}

\author{
Krzysztof Młynek ${ }^{1}$, Izabela Janiuk ${ }^{2}$ \\ Siedlce University of Natural Sciences and Humanities, ${ }^{1}$ Department of Cattle Breeding and Milk Evaluation, \\ ${ }^{2}$ Department of Vertebrate Morphology, Siedlce, Poland \\ Received November 26, 2012 \\ Accepted May 29, 2013
}

\begin{abstract}
Despite numerous published studies, the relationship between the amount of secreted cocaine and amphetamine regulated transcript and the daily body weight gain has still not been well explained. The aim of this study was to determine the incidence of cocaine and amphetamine regulated transcript in the outlet wall of the abomasum of bulls with different daily weight gains. The study was performed on 15 bulls, breed crosses of local black and white milk cattle and Limousin bulls. The animals were slaughtered at the mean age of 543-549 days and body weight of 441.0-491.4 kg. Fragments of the outlet wall of the abomasum were sampled for analyses during routine slaughter. Immunohistochemical assays showed that slowly growing bulls $(803 \mathrm{~g} /$ day $)$ had significantly $(P \leq 0.05)$ fewer positive structures of cocaine and amphetamine regulated transcript (by $1.65 \times$ on average) compared to bulls with large daily weight gains (905 g/day). This tendency was also observed in the case of cocaine and amphetamine regulated transcript distribution in particular layers of the abomasum wall. The most numerous positive structures of cocaine and amphetamine regulated transcript were found in the nerve fibres of the muscularis and in the muscle plexus, whereas they were evidently less numerous in the submucous plexus. Our results suggest that the number of cocaine and amphetamine regulated transcript immunopositive structures is associated with the growth intensity of the animals, and frequent occurrence of this neuropeptide in the nerve fibres and the muscular plexus proves its role in the control of stomach emptying.
\end{abstract}

Stomach, wall abomasum, bulls, immunohistochemistry

A functional link that integrates the alimentary tract and the encephalon is represented by numerous compounds, peptides and neurotransmitters. These substances work antagonistically, some of them are orexigenic, while others are anorexigenic (Vic entic and Jones 2007). The least known representative of the orexia control agents is the peptide, cocaine and amphetamine regulated transcript - CART (Spiess et al. 1981; Douglass et al. 1995), which is also located in the alimentary tract, the intestine and the stomach (Asnicar et al. 2001; Kasacka et al. 2012;) and in the pancreas (Arciszewski et al. 2008). Earlier studies connected with the identification of CART in the alimentary tract showed its role in the secretion of gastric juice, stomach emptying and intensified colon peristalsis (Okumura et al. 2000). Only a few of them provide information on the presence of the peptide in question in the alimentary tract of the pig, sheep, cattle and humans (Arciszewski et al. 2009; Kasacka et al. 2012; Wojtkiewicz et al. 2012). The data for cattle are incomplete due to considerable difficulty in obtaining experimental material. The existing papers discuss CART location in the nervous system or CART expression in various cattle breeds (Zhang et al. 2008). Despite the available knowledge on the CART peptide, precise answers to the question of its role in particular organs, including the stomach, are missing.

The intake of large volumes of feed by cattle must be associated with an efficacious use of the nutrients contained therein. This principally concerns those compounds that can be broken down through bacteria-aided digestion, such as proteins or methionine

Address for correspondence:

Krzysztof Młynek, PhD, M.Sc

Department of Cattle Breeding and Milk Evaluation

Siedlce University of Natural Sciences and Humanities

Prusa 14, 08-110 Siedlce, Poland 
and lysine, a deficiency of which may limit production indicators of cattle (Sýkora et al. 2007). Effective digestibility is also associated with the performance of the structures in the abdominal wall of ruminants. Julius et al. (2011) have shown that the administration of feeds with a high concentration of nutrients in the dry matter may lead to changes that disturb this process. The effect of these stimuli is connected with the behavioral aspect of feeding, specifically with the control and metabolism of digestion. In the case of cattle, due to the specificity of digestion, feeding and body weight gains highly affect production. The aim of this study is identification of CART distribution in the abomasum outlet wall of bulls with different growth rates.

\section{Materials and Methods}

\section{Animals}

The material consisted of 15 bulls, offspring of Polish Lowland Black-and-White cows mated with Limousin bulls. The bulls were kept under similar conditions but came from 3 farms. Fattening started when the calves weighed 150-180 kg (approximately after 6 months). In the autumn-winter period, the animals were fed hay ad libitum and corn silage (approximately $10 \mathrm{~kg} / 24 \mathrm{~h}$ ). In the spring-summer period, green fodder and straw were provided ad libitum and compound cereal meal was used as a supplement to the main diet (approximately 1.0 $\mathrm{kg} / 24 \mathrm{~h}$ throughout the fattening).

Before slaughter, the extent of daily weight gains (GI g/day) was computed for all the animals. The animals selected for the analyses were classified in two groups of daily weight gains (the limit value was GI g/day $=850$ $\mathrm{g}$ /day). The bulls were slaughtered at a mean age of $543 \pm 32$ days; the first group was characterised by a high GI g/day $-549 \pm 21$ days $(n=8)$, the second group with a low GI g/day - $537 \pm 27$ days $(n=7)$. The body weight of the slaughtered animals ranged from $491.4 \pm 28 \mathrm{~kg}$ to $441.0 \pm 21 \mathrm{~kg}$, respectively.

\section{Sampling}

The experimental material was sampled during a routine carcass dissection procedure applied at meat plants. In a time below $30 \mathrm{~min}$ post mortem, the stomachs of the analysed bulls were prepared. Outlet area fragments of the abomasum were sampled (each time from the same spot). The tissue was ex tempore fixed in $4 \%$ buffered formalin for $72 \mathrm{~h}$ at room temperature. Subsequently, paraffin blocks were made based on standard procedures.

\section{Microscopy analysis}

The samples were analyzed and photographed with an Olympus BX41 light microscope with a video channel connected to a PC equipped with a Cell-B image analysis program (Olympus 114 Corp., Tokyo, Japan). When recording the microscopic images, particular attention was paid to the distribution of the structures showing immunoreactivity to the analysed antigen. Morphometric analysis was applied to diffuse neuroendocrine system cells that produced dark brown stains. Immunopositive neuroendocrine cells were counted in 10 randomly selected fields of vision $\left(0.785 \mathrm{~mm}^{2}\right)$, at a $200 \times$ zoom $(20 \times$ lens and $10 \times$ eyepiece $)$. The semi-quantitative evaluation of the density of CART-immunoreactive nerve fibres and a structure scale were used for the determination of the density of the remaining structures, where: (0) - none found, (1) - single, (2) - few, (3) - moderate number and (4) - dense.

\section{Immunohistochemistry}

In the immunohistochemical study, the EnVision technique was used according to Herman and Elfont (1991). The paraffin blocks were cut into $4 \mu \mathrm{m}$ sections and mounted onto Superfrost Plus slides (Menzel, Braunschweig, Germany) and dried overnight at $37^{\circ} \mathrm{C}$ followed by $1 \mathrm{~h}$ at $60^{\circ} \mathrm{C}$. Immunohistochemistry was performed using the EnVision (+) HRP Rabbit Detection System (No: K4011, Dako, Glostrup, Denmark). Sections were deparaffinized in xylene and rehydrated in decreasing concentrations of pure ethanol. For antigen retrieval, the sections were subjected to pretreatment in a pressure chamber heating for $1 \mathrm{~min}$ at $21 \mathrm{psi}$ [One pound force per square inch (1 psi) equates to $6.895 \mathrm{kPa}$, conversion factor provided by United Kingdom National Physical Laboratory] at $125^{\circ} \mathrm{C}$ using Target retrieval solution $\mathrm{pH}=9.0$ (No: S2367). After being cooled to room temperature, sections were incubated with Peroxidase blocking reagent for 10 min to block endogenous peroxidase activity. Cocaine and amphetamine regulated transcript (Phoenix Pharmaceuticals, CA, Burlingame, USA, code H 003-61) was diluted $(1: 5,000)$ in antibody diluent (No: S 0809).

The sections were incubated overnight at $4{ }^{\circ} \mathrm{C}$ in a humidified chamber with the diluted antibody, followed by incubation with Labelled Polymer for $1 \mathrm{~h}$. Bound antibodies were visualized by 1-min incubation with liquid 3,3'-diaminobenzidine substrate chromogen. The sections were finally counterstained in haematoxylin QS (H-3404 Vector), mounted, and evaluated under light microscope. Appropriate washing with Wash Buffer S 3006 (Dako) was performed between each step. The specificity test performed for the cocaine and amphetamine regulated transcript (CART) antibody included: negative control, where the antibodies were replaced by normal rabbit serum (Vector Laboratories, Burlingame, USA) at the respective dilution and positive control was done 
for specific tissue recommended by producer; for bovine CART it is human paraventricular nucleus of the hypothalamus.

\section{Statistical analysis}

Statistical analysis involved the determination of the homogeneity of the daily weight gains of the animals $\left(\mathrm{GI}_{\mathrm{g} / \mathrm{day}}\right)$ in each group. Levene's variance homogeneity test was used for this purpose. The $\mathrm{F}$ value in this test amounted to 0.241 and $P=0.082$. Further statistical procedure involved the calculation of the following indicators for the analysed groups $\left(\mathrm{GI}_{\mathrm{g} / \mathrm{day}}\right)$ and three abomasum wall structures: arithmetic mean $(\overline{\mathrm{x}})$, extreme values (min and max) and standard deviation (SD). The study of the results included variance analysis of the animal groups with different growth intensity and of the three abomasum structures in question. Differences between the mean values were investigated with Duncan's test at $P \leq 0.05$.

\section{Results}

Table 1 shows daily body weight gains (g/day) and the number of cocaine and amphetamine regulated transcript immunopositive structures (CART-IR) in the abomasal outlet area of bulls with different growth intensities. As evidenced by the data from the table, the most numerous structures with positive immunohistochemical reaction, indicating the neuropeptide presence, were identified in the bulls from the second group with smaller daily gains. The bulls with the growth of $803 \mathrm{~g} /$ day had a mean number of CART-IR neuroendocrine cells of 2.90 , which was on average 1.65 more compared to the group in which the mean gains were greater at a mean level of $905 \mathrm{~g} /$ day.

Table 1. Daily body weight gains (g/day) and the number of cocaine and amphetamine regulated transcript immunopositive structures (CART-IR) in the abomasal outlet area of bulls with different growth intensities.

\begin{tabular}{lccccc}
\hline \multirow{2}{*}{$\begin{array}{l}\text { Growth intensity } \\
(\mathrm{n}=15)\end{array}$} & $\begin{array}{c}\text { Daily body gains } \\
(\mathrm{g} / \text { day })\end{array}$ & $\begin{array}{c}\text { Number of } \\
\text { CART-IR cells }\end{array}$ & Submucous plexus & $\begin{array}{c}\text { Nerve fibres } \\
\text { innervating } \\
\text { the muscularis }\end{array}$ & Myenteric plexus \\
\hline High $(\mathrm{n}=8)$ & $905^{\mathrm{a}} \pm 19$ & $1.25^{\mathrm{a}} \pm 0.51$ & $1.05^{\mathrm{a}} \pm 0.10$ & $2.73^{\mathrm{a}} \pm 0.86$ & $2.25^{\mathrm{a}} \pm 0.50$ \\
Low $(\mathrm{n}=7)$ & $803^{\mathrm{b}} \pm 38$ & $2.90^{\mathrm{b}} \pm 0.74$ & $1.63^{\mathrm{b}} \pm 0.48$ & $3.75^{\mathrm{b}} \pm 0.50$ & $3.37^{\mathrm{b}} \pm 0.75$ \\
Medium & $854 \pm 61$ & $2.07 \pm 1.06$ & $1.34^{1} \pm 0.29$ & $3.24^{2} \pm 0.68$ & $2.81^{2} \pm 0.63$ \\
Min & 765 & 0.8 & 1.0 & 2.0 & 2.0 \\
Max & 924 & 3.9 & 2.0 & 4.0 & 4.0 \\
\hline
\end{tabular}

Data are expressed as $\overline{\mathrm{x}} \pm \mathrm{SD}$, differences between the mean values: ${ }^{\mathrm{a}, \mathrm{b}, \mathrm{c}} P \leq 0.05$ in columns, ${ }^{1,2,3} P \leq 0.05$ in rows

The observed diffuse neuroendocrine system cells had various shapes, ranging from pyramidal through oval to polygonal. The cells were dispersed as single units in the entire abomasum wall or formed clusters composed of several cells (3-5).

Based on the obtained microscopic images of the abomasal wall (Plate VI, Fig. 1), it was also shown that, on average, the most CART containing structures were present in the nerve fibres innervating the muscularis and in the myenteric plexus (Table 1). Differences between these two abomasum wall structures and the mean number of CART-IR structures found in Meissner's submucous plexus (1.34, on average) amounted to a mean of 1.69 and were significant $(P \leq 0.05)$.

\section{Discussion}

It is a known fact that one of the most important tasks for each living organism is the maintenance of homeostasis, i.e. a state of relative balance in relation to changing exterior and interior conditions. Through evolution numerous control mechanisms 
have developed that transmit indispensable information for the maintenance of the energy balance in the organism. One of the mechanisms is represented by the food intake control system that includes nerve centers located in the hypothalamus that act by the agency of cerebral-gastric-intestinal peptides. The cerebral-gastric-intestinal axis plays an essential role in the appetite control mechanism both at the level of the central nervous system and at the level of the peripheral effectors, i.e. the alimentary tract organs.

The knowledge of specific peptides in the group of neuropeptides that affect the functioning of the alimentary duct has been vastly expanded over the last several decades. The relationship between cocaine and amphetamine administration and a considerable increase in specific mRNA expression in the rat corpus striatum shown by Douglass et al. (1995) made it possible to more precisely explore the role these peptides play in the physiology of the animal gastro-intestinal tract.

The current knowledge of CART incidence in ruminants is incomplete, since it only refers to sheep and cattle (Zhang et al. 2008; Arciszewski et al. 2009). In the case of bovine studies performed inthe last years are fragmentary and concern the expression of this neuropeptide in the centers nerves system in different cattle breeds (Zhang et al. 2008). The results of these authors have shown a relationship between the amount of secreted CART and the daily body weight gains of the animals. The abomasal walls of the bulls whose mean gains amounted to $906 \mathrm{~g} /$ day were found to contain distinctly fewer CART-positive structures. Unfortunately, there are no publications dealing with this issue in available literature.

As regards the assessment of CART-IR structures in the abomasal outlet wall in the muscularis and the muscular plexus, the dense web of CART-positive nerve fibres was similar to those found in the intestinal system of rodents (Ellis and Mawe 2003), pigs (Gonkowski et al. 2009; Wojtkiewicz et al. 2012) and humans (Kasacka et al. 2012). Despite the fact that the results stem from studies of monogastric organisms, this suggests that digestion control mechanisms have a similar origin.

A lower number of CART-IR structures in the submucous plexus, however on the large intestine of pigs, was also observed by Gonkowski et al. (2009). Similar interrelation was identified in the case of numerous CART-IR positive structures within the gastrointestinal tract of the rat (Ekblad et al. 2003), in the intestine of the guinea pig and pig (Ellis and Mawe 2003; Wojtkiewicz et al. 2012). They found that the cells of the diffuse cell system also turned out to be a source of the CART peptide. The results proved convergent with the results of Ekblad et al. (2003), whereas Wierup et al. (2007) did not identify CART presence in pig neuroendocrine cells.

Despite the available information on CART distribution and active mechanisms in the brain, alimentary tract and endocrine glands of many animal species, its participation in stomach control processes remains unclear and requires further research.

The results of our study showed the relationship between the number of CART-positive structures and daily body weight gains of the analysed animals. The most numerous CARTcontaining structures were identified in the group of bulls characterised by low daily weight gains. An already well known function of CART in the gastrointestinal tract area is its strong neuroprojective effect that consists in its co-occurrence with numerous biologically active substances. Cocaine and amphetamine regulated transcript usually co-acts with such compounds as calbidin and nitric oxide synthase (Ellis and Mawe 2003), calcitonin gene related peptide (Wierup et al. 2007) and the vasoactive intestinal peptide (Wojtkiewicz et al. 2012).

In light of the obtained results it must be stated that there is a relationship between the amount of secreted CART peptide and the daily body weight gain. The location and differences in the number of CART-LI structures observed in the abomasal wall indicate 
CART participation in the endogenous regulation of stomach emptying and the control of secretory functions.

\section{References}

Arciszewski MB, Barabasz S, Skobowiat C, Maksymowicz W, Majewski M 2009: Immunodetection of cocaineand amphetamine-regulated transcript in the rumen, reticulum, omasum and abomasum of the sheep. Anat Histol Embryol 38: 62-67

Arciszewski MB, Całka J, Majewski M 2008: Cocaine- and amphetamine-regulated transcript (CART) is expressed in the ovine pancreas. Ann Anat 190: 292-299

Asnicar MA, Smith DP, Yang DD, Heiman ML, Fox N, Chen YF, Hsiung HM, Köster A 2001: Absence of cocaineand amphetamine-regulated transcript results in obesity in mice fed a high caloric diet. Endocrinology 142: 4394-4400

Bai F, Sözen MA, Lukiw WJ, Argyropoulos G 2005: Expression of AgRP, NPY, POMC and CART in human fetal and adult hippocampus. Neuropeptides 39: 439-443

Černík J, Štercová E, Sterc J, Fictum P, Luňáček J, Halouzka R 2011: The effect of intensive fattening of bulls with a high-concentrate diet on ruminal mucosa - a morphometric study. Acta Vet Brno 80: 275-279

Douglass J, McKinzie AA, Couceyro P 1995: PCR differential display identifies a rat brain mRNA that is transcriptionally regulated by cocaine and amphetamine. J Neurosci 15: 2471-2481

Ekblad E, Kuhar M, Wierup N, Sundler F 2003: Cocaine- and amphetamine-regulated transcript: distribution and function in rat gastrointestinal tract. Neurogastroenterol Motil 15: 545-557

Ellis LM, Mawe GM 2003: Distribution and chemical coding of cocaine- and amphetamine-regulated transcript peptide (CART)-immunoreactive neurons in the guinea pig bowel. Cell Tissue Res 312: 265-274

Gonkowski S, Burliński P, Skobowiat C, Majewski M, Arciszewski MB, Radziszewski P, Całka J 2009: Distribution of cocaine- and amphetamine-regulated transcript-like immunoreactive (CART-LI) nerve structures in the porcine large intestine. Acta Vet Hung 57: 509-520

Herman GE, Elfont EA 1991: The taming of immunohistochemistry: the new era of quality control. Biotech Histochem 66: 194-199

Kasacka I, Piotrowska Z, Car H, Janiuk I, Lebkowski W 2012: Cocaine- and amphetamine-regulated transcript: identification and distribution in human gastrointestinal tract. J Biol Regul Homeost Agents 26: 419-428

Sýkora T, Rabišková M, Třináctý J, Vetchý D, Häring A, Dvořák P 2007: Postruminal delivery system for amino acids and proteins in cattle. Acta Vet Brno 76: 547-552.

Vicentic A, Jones DC 2007: The CART (cocaine- and amphetamine-regulated transcript) system in appetite and drug addiction. J Pharmacol Exp Ther 320: 499-506

Wierup N, Gunnarsdóttir A, Ekblad E, Sundler F 2007: Characterisation of CART-containing neurons and cells in the porcine pancreas, gastro-intestinal tract, adrenal and thyroid glands. BMC Neurosci 8: 51

Wojtkiewicz J, Gonkowski S, Bladowski M, Majewski M 2012: Characterisation of cocaine- and amphetamineregulated transcript-like immunoreactive (CART-LI) entericneurons in the porcine small intestine. Acta Vet Hung 60: 371-381

Zhang CL, Chen H, Wang YH, Lan XY, Lei CZ, Fang XT 2008: The polymorphisms of bovine cocaineand amphetamine-regulated transcripts and their associations with cattle (Bos taurus) growth traits. J Biosci 33: $365-370$ 
Plate VI

Młynek K.: Detection... pp. 253-257
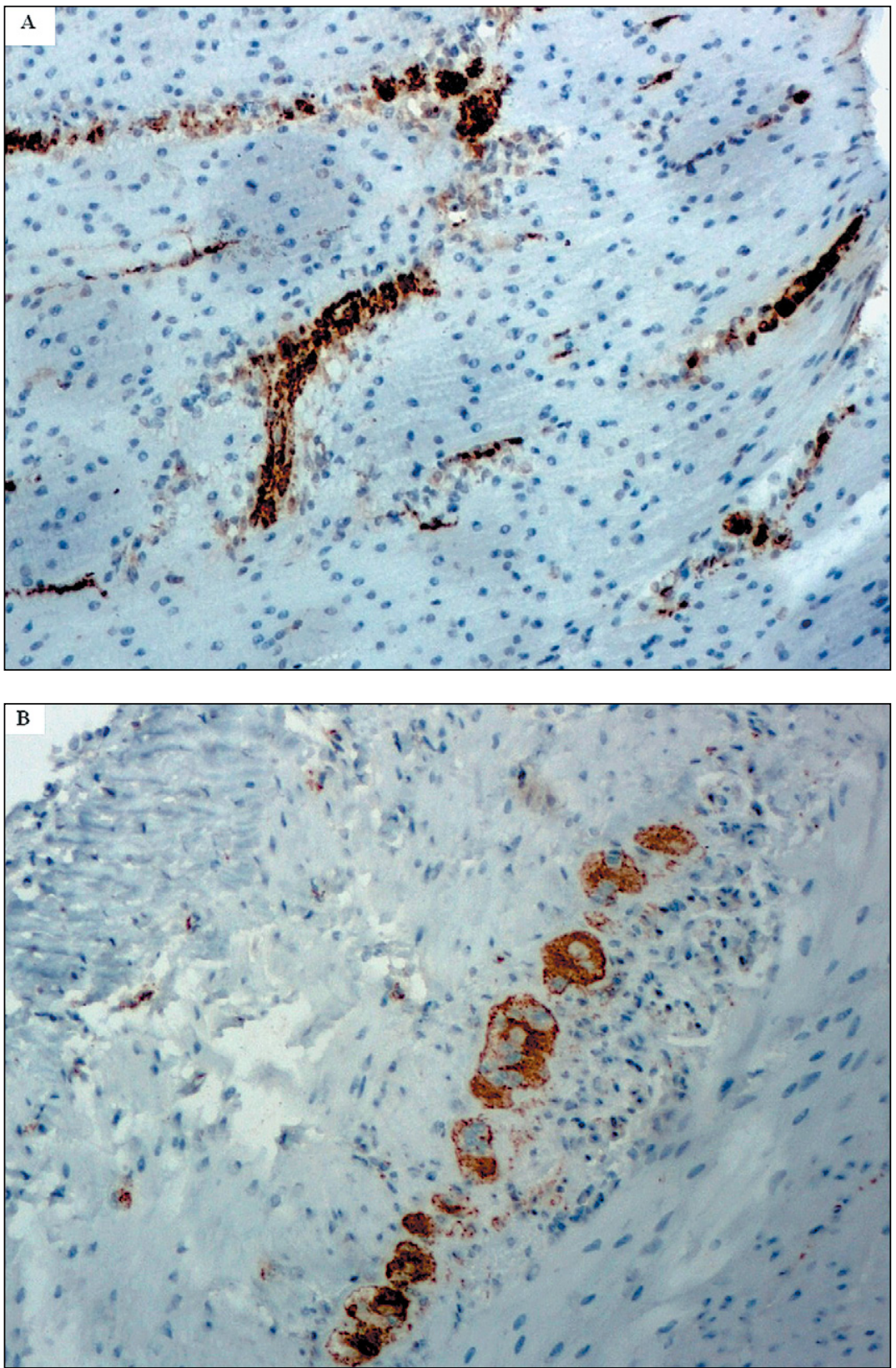

Fig. 1. Cattle pylorus immunostained for cocaine and amphetamine regulated transcript immunopositive structures.

A - photomicrograph focused on cocaine and amphetamine regulated transcript immunoreactive nerve fibres within the muscle layers, B - muscular plexus and nerve cell bodies. 